\title{
Lipid abnormalities predict progression of renal disease in patients with type 1 diabetes
}

\author{
N. Tolonen • C. Forsblom • L. Thorn • J. Wadén • \\ M. Rosengård-Bärlund • M. Saraheimo • M. Feodoroff • \\ V.-P. Mäkinen • D. Gordin • M.-R. Taskinen • \\ P.-H. Groop • FinnDiane Study Group
}

Received: 19 April 2009 /Accepted: 2 September 2009/Published online: 10 October 2009

(C) Springer-Verlag 2009

\begin{abstract}
Aims/hypothesis We studied the impact of baseline lipid variables on the progression of renal disease in a large nationwide prospective cohort of patients with type 1 diabetes. Methods A total of 2,304 adult patients with type 1 diabetes and available lipid profiles participating in the Finnish Diabetic Nephropathy Study (FinnDiane) were evaluated. Data on progression of renal disease were verified from medical files and patients were followed for $5.4 \pm 2.0$ (mean $\pm \mathrm{SD}$ ) years. Results High triacylglycerol, apolipoprotein (Apo) B, ApoA-II and $\mathrm{HDL}_{3}$-cholesterol concentrations predicted incident microalbuminuria. Progression to macroalbuminuria was predicted by high triacylglycerol and ApoB. When AER was entered into the model, triacylglycerol was no longer an
\end{abstract}

Electronic supplementary material The online version of this article (doi:10.1007/s00125-009-1541-2) includes a list of members of the

FinnDiane Study Group, which is available to authorised users.

N. Tolonen $\cdot$ C. Forsblom $\cdot$ L. Thorn $\cdot J$. Wadén $\cdot$

M. Rosengård-Bärlund $\cdot$ M. Saraheimo $\cdot$ M. Feodoroff •

V.-P. Mäkinen $\cdot$ D. Gordin $\cdot$ P.-H. Groop $(\square)$

Folkhälsan Institute of Genetics, Folkhälsan Research Center,

University of Helsinki,

Biomedicum Helsinki (C318b), Haartmaninkatu 8, PO Box 63,

00014 Helsinki, Finland

e-mail: per-henrik.groop@helsinki.fi

N. Tolonen $\cdot$ C. Forsblom $\cdot$ L. Thorn $\cdot J$. Wadén $\cdot$

M. Rosengård-Bärlund $\cdot$ M. Saraheimo $\cdot$ M. Feodoroff $\cdot$

V.-P. Mäkinen · D. Gordin · P.-H. Groop

Division of Nephrology, Department of Medicine,

Helsinki University Central Hospital,

Helsinki, Finland

M.-R. Taskinen

Division of Cardiology, Department of Medicine,

Helsinki University Central Hospital,

Helsinki, Finland independent predictor, but when patients with normal AER and microalbuminuria at baseline were pooled, triacylglycerol, $\mathrm{HbA}_{1 \mathrm{c}}$, male sex and AER were all independent predictors of renal disease. High total cholesterol, LDLcholesterol, non-HDL-cholesterol and triacylglycerol as well as low HDL-cholesterol, $\mathrm{HDL}_{2}$-cholesterol, ApoA-I and ApoA-II concentrations were predictive of progression to end-stage renal disease. However, when estimated GFR was entered into the model, only total cholesterol remained an independent predictor of progression.

Conclusions/interpretation Lipid abnormalities, particularly high triacylglycerol concentrations, increase the risk of progression of renal disease.

Keywords Albumin excretion rate Albuminuria . Apolipoprotein · Cholesterol · Diabetic nephropathy . Estimated GFR · Lipid profile · Renal disease ·

Triacylglycerol $\cdot$ Type 1 diabetes

\begin{tabular}{ll}
\multicolumn{2}{l}{ Abbreviations } \\
Apo & Apolipoprotein \\
eGFR & Estimated GFR \\
ESRD & End-stage renal disease \\
FinnDiane & Finnish Diabetic Nephropathy Study \\
IDL & Intermediate-density lipoprotein \\
Lp & Lipoprotein \\
ROC & Receiver operating characteristic \\
SBP & Systolic BP \\
VLDL & Very-low-density lipoprotein
\end{tabular}

\section{Introduction}

Cardiovascular disease is the leading cause of premature death in patients with type 1 diabetes [1] and the risk of 
cardiovascular disease in patients with diabetic nephropathy is increased tenfold [2]. Factors that are associated with the development of diabetic nephropathy include poor glycaemic control, hypertension, male sex, smoking and dyslipidaemia [3-7].

Multiple lipid abnormalities are already present at an early stage of diabetic nephropathy in patients with type 1 diabetes [8,9]. Earlier small studies have suggested that lipid variables might be involved in the development and progression of diabetic nephropathy $[10,11]$, but it can also be argued that the lipid abnormalities are merely a consequence of albuminuria. Recently, a large prospective clinical trial showed an improvement of renal function in patients treated with atorvastatin [12]. However, data on the effect of lipid-lowering agents on albuminuria are more controversial $[13,14]$.

Furthermore, most of the prospective studies included only a small number of patients, who had either developed incipient microalbuminuria or progressed from a lower to a higher stage of albuminuria. It is obvious that these studies did not have enough power to analyse a potential link between the lipid profile and the development of renal disease [10, 11, 15]. In contrast, the EURODIAB study included a large number of patients with type 1 diabetes from different parts of Europe and also a much larger number of patients who progressed with respect to their renal disease. It is, however, of note that the patients in the EURODIAB study were recruited between 1988 and 1991, represented 16 different countries with varying diets and undoubtedly represent a rather heterogeneous genetic mixture $[16,17]$.

Therefore we assessed, in a nationwide prospective and homogeneous cohort of patients with type 1 diabetes, whether baseline lipid values have an impact on the progression of renal disease. This cohort gives a unique opportunity to systematically study progression at all stages of albuminuria.

\section{Methods}

The present study is part of the ongoing prospective Finnish Diabetic Nephropathy Study (FinnDiane). FinnDiane is a nationwide, comprehensive multicentre study with the aim of identifying genetic and environmental risk factors for the development of micro- and macrovascular complications in type 1 diabetes. Consecutive adult patients from over 70 hospitals and primary healthcare centres all over Finland were asked to participate. The study protocol was approved by the local ethics committee of each participating study centre and follows the Declaration of Helsinki. All patients gave their written informed consent.

At baseline, patients underwent a thorough clinical investigation at a regular visit to the attending physician.
Baseline data were collected between 1994 and 2005. At follow-up, all available medical files including laboratory data were reviewed and any changes in renal status were verified.

Type 1 diabetes was defined as an onset of diabetes before the age of 35 years and permanent insulin treatment initiated within 1 year of diagnosis. Out of the total of 4,810 patients at baseline, complete lipid profiles were available for $4,662(97 \%)$. So far, there are prospective data on 2,412 patients with a minimum 1 year of followup time. Patients with end-stage renal disease (ESRD, $n=143$ ) were excluded from the study. Altogether, a total of 2,304 patients participated in the present study and were followed for $5.4 \pm 2.0$ years. Based on their locally measured urinary AER in two out of three consecutive overnight or $24 \mathrm{~h}$ urine collections; 1,549 patients had normal AER $(<20 \mu \mathrm{g} / \mathrm{min}$ or $<30 \mathrm{mg} / 24 \mathrm{~h}), 353$ patients microalbuminuria $(20 \leq \mathrm{AER}<200 \mu \mathrm{g} / \mathrm{min}$ or $30 \leq \mathrm{AER}$ $<300 \mathrm{mg} / 24 \mathrm{~h}$ ) and 402 patients macroalbuminuria (AER $\geq 200 \mu \mathrm{g} / \mathrm{min}$ or $\mathrm{AER} \geq 300 \mathrm{mg} / 24 \mathrm{~h}$ ) at baseline. Moreover, all AER data between baseline and the follow-up visit were reviewed, and based on the AER in any two out of three consecutive urine collections during follow-up the patient's renal status was classified in the same manner as at baseline. Progression was defined as a change from one level to a higher level of albuminuria or the development of ESRD. ESRD patients were defined as either patients undergoing dialysis or those who had received a kidney transplant. In addition to the urine collections used for classification, AER $(24 \mathrm{~h})$ was also measured with an immunoturbidimetric method centrally; the result of this measurement was used in the Cox regression analyses.

Data on medication and diabetic micro- and macrovascular complications were based on medical records and obtained by the patient's attending physician using a standardised questionnaire. BP was measured in the sitting position, after a 10 min rest, and the mean value of two measurements was used in the analyses. Smoking was defined as smoking at least one cigarette per day at the time of the baseline data collection. $\mathrm{HbA}_{1 \mathrm{c}}$ was determined at each centre by standardised immunoassays. Estimated GFR (eGFR) was calculated on the basis of a single serum creatinine measurement using both the Modification of Diet in Renal Disease $\left(\mathrm{MDRD}_{4}\right)$ equation and the CockcroftGault formula adjusted for body surface area [18, 19]. All serum lipid and lipoprotein concentrations were measured from blood samples using previously described assays [8].

Statistical analyses Data for normally distributed values are presented as means \pm SD and data for non-normally distributed values as medians with interquartile ranges. Differences between groups were analysed with ANOVA, Mann-Whitney $U$ tests or Kruskal-Wallis tests, as appro- 
priate. Categorical variables were analysed using Pearson's $\chi^{2}$ test. Pearson's correlation coefficients were used to calculate correlations between normally distributed values and Spearman's rank correlation coefficients were used for non-normally distributed values. Non-normally distributed values (triacylglycerol, AER and eGFR, as well as $\mathrm{HDL}_{2}-/$ $\mathrm{HDL}_{3}$-cholesterol and triacylglycerol/HDL-cholesterol ratios) were logarithmically transformed $\left(\log _{e}\right)$ before inclusion in the models.

To investigate the relationship between potential predictors of progression of renal disease, the Cox proportional hazards model was used, and results are presented as HRs with $95 \%$ CIs. For the analyses a standard model, including the traditional risk factors of sex, duration, $\mathrm{HbA}_{1 \mathrm{c}}$, systolic BP (SBP), BMI and smoking, was used. A more stringent level of significance $(p<0.01)$ was chosen, in order to correct for multiple testing, except in the Cox regression analyses where $p<0.05$ denoted statistical significance. To identify possible triacylglycerol thresholds predictive of renal disease, receiver operating characteristic (ROC) curves were performed. The shortest distance on the ROC curve and the maximum sum of sensitivity and specificity were considered for the determination of cut-off points. All analyses were performed using SPSS 15.0 for Windows (Chicago, IL, USA).

\section{Results}

During follow-up, 242 patients out of 2,304 (10.5\%) had progressed to a higher level of albuminuria or ESRD. One hundred (61 men/39 women) patients had developed microalbuminuria, 50 (40 men/10 women) had progressed from micro- to macroalbuminuria and 92 (56 men/ 36 women) from macroalbuminuria to ESRD. Clinical characteristics of the patients stratified by progression of renal disease are presented in Table 1. In general, progressors had higher $\mathrm{HbA}_{1 \mathrm{c}}$ and higher baseline AER and were predominantly men.

Development of microalbuminuria Table 1 also shows the association between the lipid profile and progression of renal disease. Patients who had developed microalbuminuria had higher total cholesterol, non-HDL-cholesterol, triacylglycerol, apolipoprotein (Apo) A-II and ApoB and ApoB/ ApoA-I and triacylglycerol/HDL-cholesterol ratios at baseline than patients who had not progressed.

In a Cox regression analysis, $\mathrm{HbA}_{1 \mathrm{c}}$, sex and triacylglycerol were predictors of development of microalbuminuria (Table 2). Triacylglycerol was then replaced in the model with all the other measured lipid variables, one at a time. Out of the other lipid variables, ApoB, high $\mathrm{HDL}_{3^{-}}$ cholesterol and high ApoA-II, as well as low ApoA-I/
ApoA-II ratio, were also predictors of progression (Table 3). When baseline AER was entered into the models, triacylglycerol and $\mathrm{ApoB}$ were no longer independent predictors of progression, but Apo-AII, $\mathrm{HDL}_{3}$-cholesterol and ApoAI/ApoA-II ratio remained significant in their respective models (Table 3). $\mathrm{HbA}_{1 \mathrm{c}}$ and AER were predictive of progression in all models.

When the patients were stratified into quartiles based on their triacylglycerol concentration, the cut-off points were as follows: $0.72,0.93$ and $1.27 \mathrm{mmol} / \mathrm{l}$. In an unadjusted Cox regression analysis, the HRs for the development of microalbuminuria were $2.29(95 \%$ CI $1.13-4.65)$ for the second, 2.56 (95\% CI 1.26-5.18) for the third and 3.62 (95\% CI 1.85-7.10) for the fourth quartile compared with the first quartile (Fig. 1). After adjustment for traditional risk factors, the HR for progression was 2.18 (95\% CI 1.08-4.42) for the fourth quartile compared with the first quartile.

Progression from micro- to macroalbuminuria Patients who had progressed from micro- to macroalbuminuria had higher total cholesterol, non-HDL-cholesterol, triacylglycerol and ApoB and ApoB/ApoA-I and triacylglycerol/ HDL-cholesterol ratios at baseline than patients who had not progressed (Table 1).

In Cox regression analysis, $\mathrm{HbA}_{1 \mathrm{c}}$, male sex and triacylglycerol were independent predictors of progression (Table 2). When triacylglycerol was replaced with the other lipid variables separately, high $\mathrm{ApoB}$ and ApoB/ApoA-I and triacylglycerol/HDL-cholesterol ratios were predictors of macroalbuminuria (Table 4). When baseline AER was entered into the model, only AER was predictive of progression to macroalbuminuria (Table 4).

When patients were stratified into quartiles by their triacylglycerol concentration, the cut-off values were 0.82 , 1.08 and $1.56 \mathrm{mmol} / \mathrm{l}$. In an unadjusted Cox regression analysis, the HR for progression from micro- to macroalbuminuria was 4.72 (95\% CI 1.93-11.50) for the fourth quartile compared with the first quartile (Fig. 1). After adjustment for traditional risk factors the differences between the triacylglycerol groups were no longer significant.

Progression from macroalbuminuria to ESRD Progressors from macroalbuminuria to ESRD had higher total cholesterol, LDL-, non-HDL-cholesterol, triacylglycerol and ApoB and ApoB/ApoA-I and triacylglycerol/HDL-cholesterol ratios, as well as lower $\mathrm{HDL}$ - and $\mathrm{HDL}_{2}$-cholesterol and $\mathrm{HDL}_{2}-/ \mathrm{HDL}_{3}$ cholesterol ratio and ApoA-II levels than patients who had not progressed (Table 1).

In Cox regression analysis, high SBP, low BMI and high triacylglycerol were predictive of progression (Table 2). High total cholesterol, LDL- and non-HDL-cholesterol and ApoB/ApoA-I, ApoA-I/ApoA-II and triacylglycerol/HDLcholesterol ratios, as well as low HDL- and $\mathrm{HDL}_{2}$ - 
Table 1 Clinical characteristics and lipid profiles of patients with type 1 diabetes grouped by AER status and progression of renal disease

\begin{tabular}{|c|c|c|c|c|c|c|}
\hline \multirow[t]{2}{*}{ Variable } & \multicolumn{2}{|l|}{ Normal AER } & \multicolumn{2}{|l|}{ Microalbuminuria } & \multicolumn{2}{|l|}{ Macroalbuminuria } \\
\hline & $\begin{array}{l}\text { Non- } \\
\text { progressors }\end{array}$ & Progressors & $\begin{array}{l}\text { Non- } \\
\text { progressors }\end{array}$ & Progressors & $\begin{array}{l}\text { Non- } \\
\text { progressors }\end{array}$ & Progressors \\
\hline$n$ & 1,449 & 100 & 303 & 50 & 310 & 92 \\
\hline Men $(\%)$ & 46 & $61^{*}$ & 55 & $80 * *$ & 56 & 61 \\
\hline Age (years) & $35.7 \pm 12.1$ & $34.8 \pm 12.1$ & $37.9 \pm 12.4$ & $34.8 \pm 10.9$ & $41.1 \pm 10.1$ & $40.6 \pm 9.1$ \\
\hline Age at onset (years) & $16.1 \pm 8.6$ & $15.3 \pm 8.8$ & $11.6 \pm 8.1$ & $9.7 \pm 6.4$ & $11.4 \pm 7.3$ & $12.4 \pm 7.3$ \\
\hline Diabetes duration (years) & $19.6 \pm 11.7$ & $19.5 \pm 11.5$ & $26.2 \pm 11.3$ & $25.1 \pm 10.8$ & $29.7 \pm 8.1$ & $28.3 \pm 7.4$ \\
\hline Systolic BP (mmHg) & $128 \pm 15$ & $130 \pm 15$ & $135 \pm 17$ & $135 \pm 14$ & $141 \pm 19$ & $150 \pm 21 * *$ \\
\hline Diastolic BP (mmHg) & $78 \pm 9$ & $80 \pm 10$ & $80 \pm 10$ & $83 \pm 10$ & $82 \pm 10$ & $85 \pm 10^{*}$ \\
\hline BMI $\left(\mathrm{kg} / \mathrm{m}^{2}\right)$ & $24.9 \pm 3.3$ & $25.2 \pm 3.6$ & $25.5 \pm 3.5$ & $25.4 \pm 3.8$ & $26.1 \pm 3.8$ & $25.5 \pm 4.7$ \\
\hline \multicolumn{7}{|l|}{ WHR } \\
\hline Men & $0.89 \pm 0.07$ & $0.92 \pm 0.06^{* *}$ & $0.91 \pm 0.07$ & $0.93 \pm 0.06$ & $0.94 \pm 0.07$ & $0.94 \pm 0.07$ \\
\hline Women & $0.80 \pm 0.06$ & $0.80 \pm 0.08$ & $0.82 \pm 0.06$ & $0.86 \pm 0.07$ & $0.84 \pm 0.07$ & $0.84 \pm 0.07$ \\
\hline $\mathrm{HbA}_{1 \mathrm{c}}(\%)$ & $8.2 \pm 1.4$ & $9.2 \pm 1.7 * *$ & $8.7 \pm 1.4$ & $9.8 \pm 2.0 * *$ & $8.9 \pm 1.4$ & $9.4 \pm 1.7^{*}$ \\
\hline Serum creatinine $(\mu \mathrm{mol} / \mathrm{l})$ & $83(73-92)$ & $84(75-93)$ & $87(77-98)$ & $88(81-103)$ & $113(90-141)$ & $226(149-303)^{* *}$ \\
\hline $\operatorname{AER}(\mathrm{mg} / 24 \mathrm{~h})$ & $7(5-11)$ & $15(9-29)^{* *}$ & $42(20-76)$ & $151(91-214)^{* *}$ & $350(148-857)$ & $1,450(626-2,915)^{* *}$ \\
\hline Smoking (\%) & 21 & 26 & 28 & 43 & 30 & 30 \\
\hline $\begin{array}{l}\text { Antihypertensive } \\
\text { treatment }(\%)\end{array}$ & 13 & 17 & 61 & 76 & 93 & 95 \\
\hline Lipid-lowering agents (\%) & 5 & 10 & 10 & 10 & 20 & 29 \\
\hline Total cholesterol $(\mathrm{mmol} / \mathrm{l})$ & $4.77 \pm 0.88$ & $5.10 \pm 1.04 * *$ & $4.94 \pm 0.88$ & $5.32 \pm 1.01 * *$ & $5.27 \pm 0.88$ & $5.82 \pm 1.38 * *$ \\
\hline LDL-cholesterol (mmol/l) & $2.95 \pm 0.80$ & $3.14 \pm 0.88$ & $3.07 \pm 0.79$ & $3.34 \pm 0.95$ & $3.38 \pm 0.83$ & $3.73 \pm 1.14 * *$ \\
\hline HDL-cholesterol (mmol/l) & $1.33 \pm 0.36$ & $1.30 \pm 0.37$ & $1.30 \pm 0.37$ & $1.18 \pm 0.34$ & $1.20 \pm 0.32$ & $1.09 \pm 0.42 *$ \\
\hline $\begin{array}{l}\mathrm{HDL}_{2} \text {-cholesterol } \\
(\mathrm{mmol} / \mathrm{l})\end{array}$ & $0.55 \pm 0.26$ & $0.50 \pm 0.23$ & $0.53 \pm 0.25$ & $0.45 \pm 0.20$ & $0.48 \pm 0.23$ & $0.41 \pm 0.29^{*}$ \\
\hline $\begin{array}{l}\mathrm{HDL}_{3} \text {-cholesterol } \\
(\mathrm{mmol} / \mathrm{l})\end{array}$ & $0.78 \pm 0.19$ & $0.82 \pm 0.23$ & $0.78 \pm 0.20$ & $0.74 \pm 0.18$ & $0.73 \pm 0.18$ & $0.70 \pm 0.18$ \\
\hline $\begin{array}{l}\text { Non-HDL-cholesterol } \\
(\mathrm{mmol} / \mathrm{l})\end{array}$ & $3.43 \pm 0.87$ & $3.75 \pm 1.04 * *$ & $3.62 \pm 0.88$ & $4.09 \pm 1.13^{* *}$ & $4.05 \pm 0.94$ & $4.63 \pm 1.26^{* *}$ \\
\hline Triacylglycerol $(\mathrm{mmol} / \mathrm{l})$ & $0.92(0.71-1.26)$ & $1.10(0.81-1.65)^{* *}$ & $1.05(0.80-1.47)$ & $1.56(1.04-2.22)^{* *}$ & $1.28(0.97-1.80)$ & $1.66(1.20-2.74)^{* *}$ \\
\hline ApoA-I (g/l) & $1.38 \pm 0.21$ & $1.38 \pm 0.19$ & $1.40 \pm 0.21$ & $1.37 \pm 0.21$ & $1.40 \pm 0.21$ & $1.35 \pm 0.25$ \\
\hline ApoA-II (g/l) & $0.33 \pm 0.09$ & $0.36 \pm 0.09 *$ & $0.34 \pm 0.09$ & $0.37 \pm 0.10$ & $0.34 \pm 0.08$ & $0.31 \pm 0.07^{*}$ \\
\hline ApoB (g/l) & $0.83 \pm 0.20$ & $0.93 \pm 0.22 * *$ & $0.89 \pm 0.21$ & $1.02 \pm 0.28 * *$ & $0.99 \pm 0.20$ & $1.09 \pm 0.29 * *$ \\
\hline ApoB/ApoA-I & $0.61 \pm 0.17$ & $0.68 \pm 0.17^{*}$ & $0.65 \pm 0.18$ & $0.77 \pm 0.26^{* *}$ & $0.73 \pm 0.19$ & $0.83 \pm 0.24 * *$ \\
\hline ApoA-I/ApoA-II & $4.39 \pm 1-07$ & $4.04 \pm 0.93$ & $4.29 \pm 0.92$ & $3.84 \pm 0.83$ & $4.29 \pm 0.86$ & $4.51 \pm 1.02$ \\
\hline $\mathrm{HDL}_{2}$-/HDL 3 -cholesterol & $0.68(0.49-0.92)$ & $0.59(0.42-0.80)$ & $0.66(0.49-0.87)$ & $0.58(0.44-0.79)$ & $0.67(0.43-0.86)$ & $0.51(0.31-0.82)^{*}$ \\
\hline $\begin{array}{l}\text { Triacylglycerol/HDL- } \\
\text { cholesterol }\end{array}$ & $0.71(0.51-1.05)$ & $0.85(0.57-1.41)^{* *}$ & $0.82(0.58-1.25)$ & $1.33(0.82-2.33)^{* *}$ & $1.10(0.74-1.73)$ & $1.55(0.95-3.22)^{* *}$ \\
\hline
\end{tabular}

Data are means \pm SD or median (interquartile range)

$p$ values for lipid variables are adjusted for age, sex and BMI

${ }^{*} p<0.01, * * p<0.001$ vs non-progressors

cholesterol, $\mathrm{HDL}_{2}-\mathrm{HDL}_{3}$-cholesterol ratio and ApoA-II were also predictors of progression (Table 5). When baseline eGFR was included in the models, lipid variables were no longer predictive of progression, except for total cholesterol. In this model, $\mathrm{HbA}_{1 \mathrm{c}}$, eGFR and total cholesterol were independent predictors of progression (Table 5).

When patients were stratified into quartiles of total cholesterol, the cut-off values were 4.70, 5.27 and
$5.97 \mathrm{mmol} / \mathrm{l}$. In an unadjusted Cox regression analysis, the HR for progression was 1.96 (95\% CI 1.13-3.40) for the fourth compared with the first quartile of total cholesterol. After adjustment for traditional risk factors, the differences between the groups were no longer significant. Furthermore, when patients were stratified into quartiles of triacylglycerol, the cut-off values were 1.02 , 1.36, and $2.02 \mathrm{mmol} / \mathrm{l}$. In an unadjusted Cox regression 
Table 2 Cox regression analyses with risk factors for progression of renal disease

\begin{tabular}{|c|c|c|c|c|c|c|}
\hline \multirow[t]{3}{*}{ Variable } & \multicolumn{6}{|l|}{ Progression to: } \\
\hline & \multicolumn{2}{|l|}{ Microalbuminuria } & \multicolumn{2}{|l|}{ Macroalbuminuria } & \multicolumn{2}{|l|}{ ESRD } \\
\hline & Adjusted HR (95\% CI) & $p$ value & Adjusted HR (95\% CI) & $p$ value & Adjusted HR $(95 \% \mathrm{CI})$ & $p$ value \\
\hline $\mathrm{HbA}_{1 \mathrm{c}}(\%)$ & $1.52(1.34-1.73)$ & $<0.001$ & $1.28(1.09-1.50)$ & 0.003 & $1.11(0.97-1.28)$ & NS \\
\hline Male sex (\%) & $1.83(1.19-2.82)$ & 0.006 & $2.50(1.22-5.09)$ & 0.01 & $1.06(0.68-1.65)$ & NS \\
\hline Smoking (\%) & $0.99(0.62-1.60)$ & NS & $1.48(0.80-2.72)$ & NS & $0.82(0.50-1.34)$ & NS \\
\hline $\mathrm{SBP}(\mathrm{mmHg})$ & $1.00(0.99-1.02)$ & NS & $1.00(0.98-1.02)$ & NS & $1.02(1.01-1.04)$ & $<0.001$ \\
\hline BMI $\left(\mathrm{kg} / \mathrm{m}^{2}\right)$ & $1.00(0.94-1.07)$ & NS & $1.00(0.91-1.09)$ & NS & $0.92(0.86-0.98)$ & 0.007 \\
\hline Duration (years) & $1.01(0.99-1.03)$ & NS & $1.01(0.99-1.04)$ & NS & $0.99(0.96-1.03)$ & NS \\
\hline $\log _{e}$ triacylglycerol & $1.71(1.17-2.50)$ & 0.006 & $2.69(1.53-4.71)$ & 0.001 & $2.30(1.50-3.53)$ & $<0.001$ \\
\hline
\end{tabular}

analysis, the HR for progression was 3.30 (95\% CI 1.716.36) for the fourth compared with the first quartile of triacylglycerol (Fig. 1). After adjustment for traditional risk factors, the HR for progression was 3.10 (95\% CI 1.506.39) for the fourth compared with the first quartile.

Pooled data Interestingly, when patients with normal AER and microalbuminuria were pooled, triacylglycerol, $\mathrm{HbA}_{1 \mathrm{c}}$, male sex and AER independently predicted progression of renal disease (Table 6). When triacylglycerol was replaced with the other lipid variables separately, ApoA-I/ApoA-II and $\mathrm{HDL}_{2}-\mathrm{HDL}_{3}$-cholesterol ratios also predicted progression of renal disease (Electronic supplementary material [ESM] Table 1).
When all patients were pooled, triacylglycerol, $\mathrm{HbA}_{1 \mathrm{c}}$, male sex, AER and eGFR independently predicted progression of renal disease (ESM Table 2).

ROC curves In order to identify possible triacylglycerol thresholds for the progression of renal disease, ROC curve analyses were performed. For the development of microalbuminuria the AUC was 0.63 (95\% CI 0.57-0.68), $p<$ 0.001 . For the progression from micro- to macroalbuminuria, the AUC was 0.69 (95\% CI 0.61-0.77), $p<0.001$, and for the progression to ESRD it was 0.65 (95\% CI 0.58 $0.71), p<0.001$. However, when the maximum sums of sensitivity and specificity were calculated they were not high enough to identify a clinically relevant triacylglycerol

Table 3 Lipids and lipoproteins entered separately into Cox regression models for progression to microalbuminuria adjusted for traditional risk factors or for traditional risk factors and AER

\begin{tabular}{|c|c|c|c|c|}
\hline \multirow[t]{2}{*}{ Variable } & \multicolumn{4}{|l|}{ Adjusted HR (95\% CI) } \\
\hline & Traditional risk factors $^{\mathrm{a}}$ & $p$ value & Traditional risk factors ${ }^{\mathrm{a}}$ and AER & $p$ value \\
\hline Total cholesterol (mmol/l) & $1.20(0.99-1.46)$ & NS & $1.11(0.89-1.39)$ & NS \\
\hline LDL-cholesterol (mmol/1) & $1.11(0.86-1.43)$ & NS & $1.14(0.87-1.50)$ & NS \\
\hline HDL-cholesterol (mmol/l) & $1.27(0.70-2.30)$ & NS & $1.43(0.76-2.69)$ & NS \\
\hline $\mathrm{HDL}_{2}$-cholesterol (mmol/1) & $0.72(0.29-1.83)$ & NS & $0.72(0.26-2.01)$ & NS \\
\hline $\mathrm{HDL}_{3}$-cholesterol (mmol/l) & $3.79(1.40-10.27)$ & 0.009 & $4.84(1.68-13.93)$ & 0.003 \\
\hline Non-HDL-cholesterol (mmol/l) & $1.19(0.95-1.49)$ & NS & $1.10(0.86-1.41)$ & NS \\
\hline $\log _{e}$ triacylglycerol & $1.71(1.17-2.50)$ & 0.006 & $1.18(0.76-1.82)$ & NS \\
\hline ApoA-I (g/l) & $1.44(0.53-3.95)$ & NS & $1.57(0.52-4.71)$ & NS \\
\hline ApoA-II (g/l) & $24.73(3.05-200.67)$ & 0.003 & $30.30(3.15-290.96)$ & 0.003 \\
\hline ApoB (g/l) & $2.81(1.05-7.53)$ & 0.04 & $1.82(0.61-5.42)$ & NS \\
\hline ApoB/ApoA-I & $1.88(0.58-6.11)$ & NS & $1.04(0.28-3.82)$ & NS \\
\hline ApoA-I/ApoA-II & $0.70(0.55-0.90)$ & 0.005 & $0.71(0.54-0.93)$ & 0.01 \\
\hline $\log _{e}\left(\mathrm{HDL}_{2}-\mathrm{HDL}_{3}\right.$-cholesterol $)$ & $0.71(0.50-1.03)$ & NS & $0.59(0.38-0.91)$ & 0.02 \\
\hline $\log _{e}$ (triacylglycerol/HDL-cholesterol) & $1.33(0.98-1.80)$ & NS & $1.00(0.72-1.38)$ & NS \\
\hline
\end{tabular}

${ }^{\mathrm{a}} \mathrm{HbA}_{1 \mathrm{c}}$, sex, smoking, SBP, BMI and duration of diabetes 


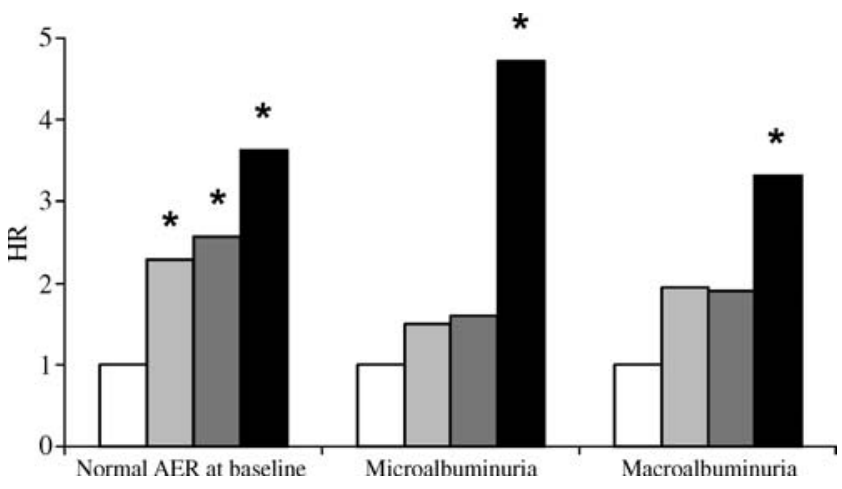

Fig. 1 HRs for progression of renal disease when patients were stratified for quartiles of triacylglycerol. Triacylglycerol ranges were: $0.31-0.72$ (white), 0.73-0.93 (light grey), 0.94-1.27 (dark grey) and 1.28-10.16 (black) mmol/l, for patients with normal AER; 0.44-0.82 (white), 0.83-1.08 (light grey), 1.09-1.56 (dark grey) and 1.57-8.82 (black) $\mathrm{mmol} / \mathrm{l}$ for patients with microalbuminuria; and $0.49-1.02$ (white), 1.03-1.36 (light grey), 1.37-2.02 (dark grey) and 2.03-11.31 (black) $\mathrm{mmol} / \mathrm{l}$ for patients with macroalbuminuria at baseline. ${ }^{*} p<$ 0.05 compared with the first triacylglycerol quartile

threshold for the progression of renal disease (ESM Fig. 1a-c).

\section{Discussion}

In this large prospective cohort of patients with type 1 diabetes we showed that lipid abnormalities, particularly high triacylglycerol concentrations, increase the risk of progression of renal disease. Triacylglycerol predicted incident microalbuminuria, but when AER was included in the model, triacylglycerol was no longer an independent predictor. AER is by definition a strong predictor of progression, since progression was defined based on a change in the degree of albuminuria. However, when patients with normal AER and microalbuminuria at baseline were pooled, triacylglycerol predicted progression of renal disease independently of AER. With regard to triacylglycerol, our results are largely in line with earlier studies showing that triacylglycerol predicts incident microalbuminuria $[11,15,16]$.

Notably, we extended this observation by studying the lipid profile in more detail, including also apolipoproteins, HDL-cholesterol subclasses and ratios. Surprisingly, high $\mathrm{HDL}_{3}$-cholesterol and ApoA-II were also predictors of microalbuminuria in Cox regression analyses, and these variables predicted the development of microalbuminuria independently of AER. The results are somewhat puzzling, since the direction of the variables changed when patients entered the later stages of diabetic nephropathy. $\mathrm{HDL}_{3}$ particles contain both ApoA-I and ApoA-II proteins as their main constituents, while the majority of ApoA-I particles resides in the $\mathrm{HDL}_{2}$-density range [20]. The impact of ApoA-II and small dense HDL particles on atherosclerosis have been controversial [21-23], but it has been speculated that HDL particles containing both ApoA-I and ApoA-II (lipoprotein (Lp)A-I-A-II) would be less effective than particles containing ApoA-I (LpA-I), with respect to reverse cholesterol transport $[24,25]$. Also, an association between new cardiovascular events and a decreased ratio of LpA-I to LpA-I-A-II particles was observed in patients with type 1 diabetes [26]. In severe renal disease $\mathrm{HDL}_{3}$ cholesterol and ApoA-II levels are often reduced, as also

Table 4 Lipids and lipoproteins entered separately into Cox regression models for progression to macroalbuminuria adjusted for traditional risk factors or for traditional risk factors and AER

\begin{tabular}{|c|c|c|c|c|}
\hline \multirow[t]{2}{*}{ Variable } & \multicolumn{4}{|l|}{ Adjusted HR (95\% CI) } \\
\hline & Traditional risk factors $^{\mathrm{a}}$ & $p$ value & Traditional risk factors ${ }^{\mathrm{a}}$ and AER & $p$ value \\
\hline Total cholesterol (mmol/1) & $1.28(0.96-1.71)$ & NS & $0.95(0.71-1.28)$ & NS \\
\hline LDL-cholesterol (mmol/l) & $1.17(0.84-1.63)$ & NS & $0.89(0.64-1.22)$ & NS \\
\hline HDL-cholesterol (mmol/1) & $0.59(0.24-1.45)$ & NS & $0.65(0.24-1.73)$ & NS \\
\hline $\mathrm{HDL}_{2}$-cholesterol (mmol/1) & $0.36(0.09-1.50)$ & NS & $0.45(0.09-2.21)$ & NS \\
\hline $\mathrm{HDL}_{3}$-cholesterol (mmol/l) & $0.85(0.18-4.08)$ & NS & $0.59(0.09-3.65)$ & NS \\
\hline Non-HDL-cholesterol (mmol/l) & $1.30(0.99-1.73)$ & NS & $0.99(0.74-1.32)$ & NS \\
\hline $\log _{e}$ triacylglycerol & $2.69(1.53-4.71)$ & 0.001 & $1.52(0.76-3.04)$ & NS \\
\hline ApoA-I (g/l) & $1.11(0.26-4.77)$ & NS & $0.65(0.13-3.30)$ & NS \\
\hline ApoA-II (g/l) & $17.93(0.73-438.79)$ & NS & $0.47(0.01-23.32)$ & NS \\
\hline ApoB (g/l) & $4.58(1.36-15.48)$ & 0.01 & $1.48(0.39-5.58)$ & NS \\
\hline ApoB/ApoA-I & $3.67(1.05-12.91)$ & 0.04 & $1.76(0.47-6.59)$ & NS \\
\hline ApoA-I/ApoA-II & $0.71(0.47-1.08)$ & NS & $0.98(0.67-1.42)$ & NS \\
\hline $\log _{e}\left(\mathrm{HDL}_{2}-/ \mathrm{HDL}_{3}\right.$-cholesterol $)$ & $0.75(0.41-1.35)$ & NS & $0.82(0.42-1.61)$ & NS \\
\hline $\log _{e}($ triacylglycerol/HDL-cholesterol) & $2.01(1.30-3.09)$ & 0.002 & $1.35(0.82-2.21)$ & NS \\
\hline
\end{tabular}

${ }^{\mathrm{a}} \mathrm{HbA}_{1 \mathrm{c}}$, sex, smoking, SBP, BMI and duration of diabetes 
Table 5 Lipids and lipoproteins entered separately into Cox regression models for progression to ESRD adjusted for traditional risk factors or for traditional risk factors and eGFR

\begin{tabular}{|c|c|c|c|c|}
\hline \multirow[t]{2}{*}{ Variable } & \multicolumn{4}{|l|}{ Adjusted HR (95\% CI) } \\
\hline & Traditional risk factors $^{\mathrm{a}}$ & $p$ value & Traditional risk factors ${ }^{\mathrm{a}}$ and $\mathrm{eGFR}$ & $p$ value \\
\hline Total cholesterol (mmol/l) & $1.45(1.19-1.78)$ & $<0.001$ & $1.35(1.05-1.73)$ & 0.02 \\
\hline LDL-cholesterol (mmol/l) & $1.37(1.07-1.75)$ & 0.01 & $1.29(0.98-1.68)$ & NS \\
\hline HDL-cholesterol (mmol/l) & $0.32(0.15-0.69)$ & 0.003 & $1.04(0.49-2.17)$ & NS \\
\hline $\mathrm{HDL}_{2}$-cholesterol $(\mathrm{mmol} / \mathrm{l})$ & $0.26(0.09-0.80)$ & 0.02 & $1.29(0.45-3.76)$ & NS \\
\hline $\mathrm{HDL}_{3}$-cholesterol $(\mathrm{mmol} / \mathrm{l})$ & $0.26(0.06-1.09)$ & NS & $0.81(0.20-3.23)$ & NS \\
\hline Non-HDL-cholesterol (mmol/1) & $1.46(1.19-1.79)$ & $<0.001$ & $1.23(0.98-1.56)$ & NS \\
\hline $\log _{e}$ triacylglycerol & $2.30(1.50-3.53)$ & $<0.001$ & $0.97(0.59-1.60)$ & NS \\
\hline ApoA-I (g/l) & $0.31(0.10-0.99)$ & 0.048 & $1.36(0.43-4.30)$ & NS \\
\hline ApoA-II (g/l) & $0.002(0.00-0.08)$ & 0.001 & $0.15(0.004-6.55)$ & NS \\
\hline ApoB (g/l) & $2.50(0.96-6.54)$ & NS & $1.43(0.53-3.86)$ & NS \\
\hline ApoB/ApoA-I & $4.26(1.53-11.84)$ & 0.006 & $1.16(0.41-3.30)$ & NS \\
\hline ApoA-I/ApoA-II & $1.39(1.09-1.78)$ & 0.008 & $1.25(0.97-1.61)$ & NS \\
\hline $\log _{e}\left(\mathrm{HDL}_{2}-/ \mathrm{HDL}_{3}\right.$-cholesterol $)$ & $0.65(0.46-0.91)$ & 0.01 & $1.03(0.69-1.53)$ & NS \\
\hline $\log _{e}$ (triacylglycerol/HDL-cholesterol) & $2.01(1.48-2.74)$ & $<0.001$ & $1.02(0.72-1.45)$ & NS \\
\hline
\end{tabular}

${ }^{\mathrm{a}} \mathrm{HbA}_{1 \mathrm{c}}$, sex, smoking, SBP, BMI and duration of diabetes

seen in this study, but the role of $\mathrm{HDL}_{3}$-cholesterol and ApoA-II in early renal disease is less clear. In the Pittsburgh Epidemiology of Diabetes Complications Study, ApoA-II was higher in patients with a duration of $>20$ years of type 1 diabetes who progressed to microalbuminuria [15]. In this study, ApoA-II was also higher in those who developed microalbuminuria, and correlated positively with triacylglycerol (Spearman $r=0.29$ ) in patients with normal AER at baseline (data not shown). Furthermore, high serum triacylglycerol results in an enrichment of HDL particles by triacylglycerol, which are a preferential substrate for hepatic lipase, and hence leads to the generation of smaller

Table 6 Cox regression analysis for progression to micro- or macroalbuminuria with risk factors for progression of renal disease

\begin{tabular}{lll}
\hline Variable & Adjusted HR $(95 \% \mathrm{CI})$ & $p$ value \\
\hline $\mathrm{HbA}_{1 \mathrm{c}}(\%)$ & $1.28(1.15-1.42)$ & $<0.001$ \\
Male sex (\%) & $1.74(1.17-2.58)$ & 0.006 \\
Smoking (\%) & $1.09(0.73-1.61)$ & $\mathrm{NS}$ \\
$\mathrm{SBP}(\mathrm{mmHg})$ & $1.00(0.98-1.01)$ & $\mathrm{NS}$ \\
$\mathrm{BMI}\left(\mathrm{kg} / \mathrm{m}^{2}\right)$ & $1.01(0.96-1.06)$ & $\mathrm{NS}$ \\
Duration (years) & $1.00(0.98-1.02)$ & $\mathrm{NS}$ \\
$\log _{e}$ triacylglycerol & $1.45(1.02-2.04)$ & 0.036 \\
$\log _{e}$ AER & $1.86(1.60-2.18)$ & $<0.001$ \\
$\log _{e}$ eGFR & $0.88(0.41-1.90)$ & $\mathrm{NS}$ \\
\hline
\end{tabular}

Patients with normal AER and microalbuminuria at baseline were pooled and denser HDL particles [27]. It is possible that this could explain the positive predictive value of $\mathrm{HDL}_{3}$-cholesterol in the development of microalbuminuria found in this study.

Serum triacylglycerol and ApoB and ApoB/ApoA-I and the triacylglycerol/HDL-cholesterol ratios were independent predictors of progression to macroalbuminuria in separate models, but neither the lipid variables nor $\mathrm{HbA}_{1 \mathrm{c}}$ remained independent predictors when AER was included in the models. However, this could have been because of lack of power, since triacylglycerol and ApoA-I/ApoA-II and $\mathrm{HDL}_{2}-\mathrm{HDL}_{3}$-cholesterol ratio predicted progression of renal disease independently of AER when patients with normal AER and microalbuminuria were pooled. In the EURODIAB and Pittsburgh Epidemiology of Diabetes Complications studies, triacylglycerol did not predict the progression to macroalbuminuria $[17,28]$.

Progressors from macroalbuminuria to ESRD showed multiple lipid abnormalities, and progression was predicted by high triacylglycerol and SBP, and surprisingly by low BMI. However, it is well known that optimal nutrition is essential for the prognosis of patients with ESRD and it can be argued that a higher BMI could be protective also with respect to the development of ESRD. In our study of the metabolic syndrome as a risk factor for progression of renal disease [29], we also found that the relationship between obesity and development of ESRD might be inverted or Ushaped. When baseline eGFR was entered into the model, triacylglycerol was no longer an independent predictor. It is of note that progression from macroalbuminuria to ESRD was based on a change in renal function. Therefore, it is not 
unexpected that the inclusion of eGFR in the model weakens the predictive power of other risk factors. Several other lipid variables also predicted progression to ESRD, for example high total cholesterol, LDL-cholesterol and non-HDL-cholesterol and the ApoB/ApoA-I ratio, as well as low HDL-cholesterol and ApoA-II. It is of note that total cholesterol remained an independent predictor even after the inclusion of eGFR. In the WHO MSWDD study, triacylglycerol was predictive of renal failure in patients with type 2 diabetes, but not in patients with type 1 diabetes [30]. However, this could have been because of the power, since the number of progressors was lower and triacylglycerol was only measured in a sub-sample of patients.

ApoB is the main protein moiety of LDL, intermediatedensity lipoprotein (IDL) and very-low-density lipoprotein (VLDL) particles and its concentrations are a good estimate of the total particle number of these highly atherogenic particles [31]. Each of these particles has one molecule of ApoB, but over $90 \%$ of circulating ApoB are constituents of the LDL particles [32]. However, high ApoB concentrations have been associated with cardiovascular disease independently of LDL-cholesterol levels [33]. In this study, ApoB was higher in patients who progressed at all stages of renal disease. It was also a predictor of progression to micro- and macroalbuminuria in Cox regression analyses, but when AER was entered in the models, ApoB was no longer an independent predictor. In the Pittsburgh Epidemiology of Diabetes Complications Study, ApoB was also higher in patients who progressed to micro- or macroalbuminuria, but it was not an independent predictor of progression $[15,34]$.

Serum levels of triacylglycerol are strongly related to glycaemic control $[8,35]$. However, triacylglycerol predicted progression from normal AER to microalbuminuria independently of $\mathrm{HbA}_{1 \mathrm{c}}$. Our results therefore support an additive effect of triacylglycerol on the progression of renal disease beyond glycaemic control.

Small dense LDL particles are thought to be particularly atherogenic and may damage the renal endothelium or mesangium [36]. We did not measure LDL particle size, but since the LDL particle size correlates inversely with triacylglycerol [37], it is likely that our patients with high triacylglycerol levels will also have a preponderance of small LDL particles. LDL-cholesterol calculated with the Friedewald formula was not a significant predictor of progression of renal disease, but there are some limitations with respect to the calculated LDL-cholesterol. It is less accurate as plasma triacylglycerol concentrations increase, and it contains both LDL-cholesterol and IDL-cholesterol. When new build-up regression models were used to calculate IDL- and LDL-cholesterol separately from the Friedewald inputs, total cholesterol, triacylglycerol, HDLcholesterol and IDL-cholesterol was associated with mor- tality in the FinnDiane Study population, but LDLcholesterol was not [38].

In this study, there were significant differences in nonHDL-cholesterol concentrations between progressors and non-progressors at all stages of renal disease, whereas the LDL-cholesterol concentrations were only significantly higher in patients who progressed to ESRD. Studies have shown that in the presence of high triacylglycerol, LDLcholesterol concentrations alone do not seem to explain the risk associated with an atherogenic lipid profile. Therefore, the use of non-HDL-cholesterol has been suggested, as it includes the cholesterol of VLDL, IDL, LDL and lipoprotein(a), which are all considered to be atherogenic particles [39]. In a pooled analysis of two large prospective clinical trials non-HDL-cholesterol and ApoB were more closely associated with cardiovascular outcome than LDLcholesterol in patients receiving statin therapy [40].

The strength of our study is that the patients in this largescale prospective study were evenly spread all over the country, and account for about $8 \%$ of all patients with type 1 diabetes in Finland. Further, all lipid variables were measured in the same laboratory, specialising in lipid research. Thus, this cohort is ideal for a detailed study of lipid abnormalities. An additional strength is that the progression of renal disease was ascertained after a careful review of the medical files. Therefore the follow-up was not dependent on the patient's participation in the study, only on their regular visits to their physician.

In conclusion, lipid abnormalities, particularly high triacylglycerol concentrations, increase the risk of progression of renal disease. Whether lower lipid targets than those currently recommended would be beneficial with regard to progression of renal disease remains an open question.

Acknowledgements The study was supported by the Folkhälsan Research Foundation, the Wilhelm and Else Stockmann Foundation, the Sigrid Juselius Foundation, the Liv och Hälsa Foundation, the Waldemar von Frenckell Foundation, the Finnish Medical Society and the European Commission (QLG2-CT-2001-01669). The skilled assistance of our laboratory technicians S. Lindh, A. Sandelin, H. Hilden, H. Perttunen-Mio, V. Naatti, S. Ström and J. Thorn is gratefully acknowledged. Finally, we acknowledge physicians and nurses at each study centre (ESM).

Duality of interest The authors declare that there is no duality of interest associated with this manuscript.

\section{References}

1. Laing SP, Swerdlow AJ, Slater SD et al (1999) The British Diabetic Association cohort study, II: cause-specific mortality in patients with insulin-treated diabetes mellitus. Diabet Med $16: 466-471$

2. Tuomilehto J, Borch-Johnsen K, Molarius A et al (1998) Incidence of cardiovascular disease in type 1 (insulin-dependent) 
diabetic subjects with and without diabetic nephropathy in Finland. Diabetologia 41:784-790

3. The Diabetes Control and Complications (DCCT) Research Group (1995) Effect of intensive therapy on the development and progression of diabetic nephropathy in the Diabetes Control and Complications Trial. Kidney Int 47:1703-1720

4. Parving HH, Hommel E (1989) Prognosis in diabetic nephropathy. BMJ 299:230-233

5. Andersen AR, Christiansen JS, Andersen JK, Kreiner S, Deckert $\mathrm{T}$ (1983) Diabetic nephropathy in type 1 (insulin-dependent) diabetes: an epidemiological study. Diabetologia 25:496-501

6. Sawicki PT, Didjurgeit U, Muhlhauser I, Bender R, Heinemann L, Berger M (1994) Smoking is associated with progression of diabetic nephropathy. Diabetes Care 17:126-131

7. Mulec H, Johnsen SA, Wiklund O, Bjorck S (1993) Cholesterol: a renal risk factor in diabetic nephropathy? Am J Kidney Dis 22:196-201

8. Tolonen N, Forsblom C, Thorn L, FinnDiane Study Group et al (2008) Relationship between lipid profiles and kidney function in patients with type 1 diabetes. Diabetologia 51:12-20

9. Groop PH, Elliott T, Ekstrand A et al (1996) Multiple lipoprotein abnormalities in type I diabetic patients with renal disease. Diabetes 45:974-979

10. Thomas MC, Rosengard-Barlund M, Mills V et al (2006) Serum lipids and the progression of nephropathy in type 1 diabetes. Diabetes Care 29:317-322

11. Hadjadj S, Duly-Bouhanick B, Bekherraz A et al (2004) Serum triglycerides are a predictive factor for the development and the progression of renal and retinal complications in patients with type 1 diabetes. Diabetes Metab 30:43-51

12. Shepherd J, Kastelein JJ, Bittner V, Treating to New Targets, Investigators et al (2007) Effect of intensive lipid lowering with atorvastatin on renal function in patients with coronary heart disease: The treating to new targets (TNT) study. Clin J Am Soc Nephrol 2:1131-1139

13. Atthobari J, Brantsma AH, Gansevoort RT, PREVEND Study Group et al (2006) The effect of statins on urinary albumin excretion and glomerular filtration rate: results from both a randomized clinical trial and an observational cohort study. Nephrol Dial Transplant 21:3106-3114

14. Sandhu S, Wiebe N, Fried LF, Tonelli M (2006) Statins for improving renal outcomes: a meta-analysis. J Am Soc Nephrol 17:2006-2016

15. Coonrod BA, Ellis D, Becker DJ et al (1993) Predictors of microalbuminuria in individuals with IDDM. Pittsburgh Epidemiology of Diabetes Complications Study. Diabetes Care 16:1376-1383

16. Chaturvedi N, Bandinelli S, Mangili R, Penno G, Rottiers RE, Fuller JH (2001) Microalbuminuria in type 1 diabetes: rates, risk factors and glycemic threshold. Kidney Int 60:219-227

17. Giorgino F, Laviola L, Cavallo Perin P, Solnica B, Fuller J, Chaturvedi $N$ (2004) Factors associated with progression to macroalbuminuria in microalbuminuric type 1 diabetic patients: the EURODIAB Prospective Complications Study. Diabetologia 47:1020-1028

18. Levey AS, Bosch JP, Lewis JB, Greene T, Rogers N, Roth D (1999) A more accurate method to estimate glomerular filtration rate from serum creatinine: a new prediction equation. Modification of diet in renal disease study group. Ann Intern Med 130:461-470

19. Cockcroft DW, Gault MH (1976) Prediction of creatinine clearance from serum creatinine. Nephron 16:31-41

20. James RW, Pometta D (1990) Immunofractionation of high density lipoprotein subclasses 2 and 3 similarities and differences of fractions isolated from male and female populations. Atherosclerosis 83:35-45

21. Sweetnam PM, Bolton CH, Downs LG et al (2000) Apolipoproteins A-I, A-II and B, lipoprotein(a) and the risk of ischaemic heart disease: The Caerphilly Study. Eur J Clin Invest 30:947-956
22. O'Brien T, Nguyen TT, Hallaway BJ et al (1995) The role of lipoprotein A-I and lipoprotein A-I/A-II in predicting coronary artery disease. Arterioscler Thromb Vasc Biol 15:228-231

23. Birjmohun RS, Dallinga-Thie GM, Kuivenhoven JA et al (2007) Apolipoprotein A-II is inversely associated with risk of future coronary artery disease. Circulation 116:2029-2035

24. Barter PJ, Rye KA (1996) High density lipoproteins and coronary heart disease. Atherosclerosis 121:1-12

25. Alaupovic P, Mack WJ, Knight-Gibson C, Hodis HN (1997) The role of triglyceride-rich lipoprotein families in the progression of atherosclerotic lesions as determined by sequential coronary angiography from a controlled clinical trial. Arterioscler Thromb Vasc Biol 17:715-722

26. Groop PH, Thomas MC, Rosengard-Barlund M et al (2007) HDL composition predicts new-onset cardiovascular disease in patients with type 1 diabetes. Diabetes Care 30:2706-2707

27. Hopkins GJ, Barter PJ (1986) Role of triglyceride-rich lipoproteins and hepatic lipase in determining the particle size and composition of high density lipoproteins. J Lipid Res 27:1265-1277

28. Orchard TJ, Chang YF, Ferrell RE, Petro N, Ellis DE (2002) Nephropathy in type 1 diabetes: a manifestation of insulin resistance and multiple genetic susceptibilities? Further evidence from the Pittsburgh Epidemiology of Diabetes Complication Study. Kidney Int 62:963-970

29. Thorn LM, Forsblom C, Waden J, on behalf of the FinnDiane Study Group et al (2009) he metabolic syndrome as a risk factor for cardiovascular disease, mortality, and progression of diabetic nephropathy in type 1 diabetes. Diabetes Care 32:950-952

30. Colhoun HM, Lee ET, Bennett PH et al (2001) Risk factors for renal failure: the WHO multinational study of vascular disease in diabetes. Diabetologia 44:S46-S53

31. Sniderman AD, Pedersen T, Kjekshus J et al (1997) Putting lowdensity lipoproteins at center stage in atherogenesis. Am J Cardiol 79:64-67

32. Durrington PN, Bolton CH, Hartog M et al (1978) Serum and lipoprotein apolipoprotein $\mathrm{B}$ levels in normal subjects and patients with hyperlipoproteinaemia. Clin Chim Acta 82:151-160

33. Westerveld HT, van Lennep JE, van Lennep HW et al (1998) Apolipoprotein B and coronary artery disease in women: a crosssectional study in women undergoing their first coronary angiography. Arterioscler Thromb Vasc Biol 18:1101-1107

34. Yishak AA, Costacou T, Virella G et al (2006) Novel predictors of overt nephropathy in subjects with type 1 diabetes. A nested case control study from the Pittsburgh epidemiology of diabetes complications cohort. Nephrol Dial Transplant 21:93-100

35. DCCT Research Group (1992) Lipid and lipoprotein levels in patients with IDDM diabetes control and complication. Trial experience. Diabetes Care 15:886-894

36. de Boer IH, Astor BC, Kramer H et al (2008) Lipoprotein abnormalities associated with mild impairment of kidney function in the multi-ethnic study of atherosclerosis. Clin J Am Soc Nephrol 3:125-132

37. Taskinen MR (2005) Type 2 diabetes as a lipid disorder. Curr Mol Med 5:297-308

38. Niemi J, Mäkinen V-P, Heikkonen J et al (2009) Estimation of VLDL, IDL, LDL, HDL(2), apoA-I and apoB from the Fiedewald inputs - apoB and IDL, but not LDL, are associated with mortality in type 1 diabetes. Ann Med. doi:10.1080/07853890902893392

39. Miller M, Ginsberg HN, Schaefer EJ (2008) Relative atherogenicity and predictive value of non-high-density lipoprotein cholesterol for coronary heart disease. Am J Cardiol 101:1003-1008

40. Kastelein JJ, van der Steeg WA, Holme I, TNT Study Group, IDEAL Study Group et al (2008) Lipids, apolipoproteins, and their ratios in relation to cardiovascular events with statin treatment. Circulation 117:3002-3009 